\title{
Women in thoracic surgery: lesson learned from medical industry partners
}

\author{
Cecilia Pompili ${ }^{1}$, Annette Brüls ${ }^{2}$, Emily Elswick $^{3}$, Kate Masschelein ${ }^{4}$, Leah Backhus ${ }^{5}$ \\ ${ }^{1}$ University of Leeds, Section of Patient Centred Outcomes Research, Leeds Institute for Medical Research at St James's, Leeds, UK; ${ }^{2}$ Medela AG, \\ Baar, Switzerland; ${ }^{3}$ Medtronic, MITG, Plymouth, USA; ${ }^{4}$ Ethicon, New York, USA; ${ }^{5}$ Thoracic Surgery Division, Department of Cardiothoracic \\ Surgery, Stanford University, USA \\ Contributions: (I) Conception and design: C Pompili, L Backhus; (II) Administrative support: All authors; (III) Provision of study materials or patients: \\ All authors; (IV) Collection and assembly of data: All authors; (V) Data analysis and interpretation: All authors; (VI) Manuscript writing: All authors; \\ (VII) Final approval of manuscript: All authors. \\ Correspondence to: Cecilia Pompili MD PhD. Section of Patient Centred Outcomes Research, Leeds Institute for Medical Research at St James's, \\ University of Leeds, Thoracic Surgery Department, St James' Institute of Oncology, Beckett Street, Leeds LS9 7TF, UK. \\ Email: c.pompili@leeds.ac.uk.
}

\begin{abstract}
Medical technology has led to important achievements in surgery as minimally invasive techniques have expanded over the past several years. These innovations have changed the dynamic between industry and surgeons towards a more collaboration relationship forming partnerships important to surgical advancement and technical training opportunities. On this backdrop of transformation is growing awareness of the gender disparity that exists within the thoracic surgery workforce where we have experienced strikingly little change. At the same time, medicine is not unique with its gender disparity. As we have benefited from important partnerships to create excellence in technical innovation, so too may we benefit from drawing upon some of the successes within the medical industry towards achieving gender equity. This paper highlights examples of female leaders in the medical industry surrounding thoracic surgery, who have demonstrated excellence in the advancement and promotion of female thoracic surgeons through fellowships, mentorships or networking.
\end{abstract}

Keywords: Women surgeons; thoracic surgery; mentorship; leaders; women leadership; women in business; gender bias; diversity; mentor; role model; leadership development; gender equality; medical industry

Submitted Apr 15, 2020. Accepted for publication Jun 11, 2020.

doi: $10.21037 /$ jtd-2020-wts-02

View this article at: http://dx.doi.org/10.21037/jtd-2020-wts-02

\section{Introduction}

Women are not new to medicine but women are still outnumbered by men among the highest medical positions. Surgery and surgical subspecialties have the least gender equity for its physicians which has been widely described in the literature (1-3). Similar to the field of surgery, leaders in the world of business also experience disparities in their leadership ranks. Some organizations within the medical industry, however, have achieved comparatively more success in their commitment to the development and advancement of women compared to their counterparts.
With shifting funding streams and exponential growth in medical technology, the relationship between surgeons and our industry partners has become increasingly more important. At the same time, thoracic surgery has a growing recognition of the gender disparity that exists within our field thus we may benefit from drawing upon some of the successes within the medical industry towards achieving gender equity. This paper highlights examples of female leaders in the medical industry surrounding thoracic surgery, who have demonstrated excellence in the advancement and promotion of female thoracic surgeons through fellowships, mentorships or networking. 


\section{Annette Brüls}

\section{CEO Medela}

\section{Thriving in a man's world}

When I was invited to participate in this project, I was immediately intrigued. Though not a thoracic surgeon, I am a master in electrical engineering, a CEO of a company in the medical device industry and the mother of two boys. I definitively know what it means to juggle multiple responsibilities and to live in a man's world.

But why are we discussing women in thoracic surgery and how does it link to industry? In 2018, for the first time ever, more female than male students enrolled in medical school in the U.S. (4), yet the percentage of females specializing in surgery remains low-well below $15 \%$ (5). This is equally true for the areas of state or corporate management with $6.3 \%$ female heads of state and $6.6 \%$ female CEOs across all Fortune 500 companies (6). I do not find this surprising and think it is fair to assume that many of the challenges facing women in these typically male-dominated worlds are the same. But rather than addressing the challenges we face as women, I would like to offer my learnings and recommendations that have been helpful to me throughout my career. Though these thoughts are directed to female surgeons, I also encourage male surgeons reading this article to consider these suggestions as something to say to their female colleagues, their wife or daughters to help them thrive in their careers in the spirit of \#HeforShe.

\section{Stay autbentic}

The statistics speak for themselves-it is not common to be a female thoracic surgeon, nor is it common to be a female CEO. You are still the exception rather than the rule, so instead of denying this-or worse, complaining about itone must understand gender bias; embrace this unique situation and stay authentic.

Indeed, the consequences of gender bias manifest themselves in many ways. First, several studies have demonstrated that women with similar qualifications and experience are less likely to be hired for leadership positions and/or promoted because of their gender-by both male and female reviewers. Secondly, there is a risk that successful women will not be liked, neither by male colleagues nor by female colleagues (7). This has been beautifully demonstrated by University of Columbia's Business School. Professors provided their students with a case study of a highly successful venture capitalist, Heidi
Rozen. The key point of the exercise was that they changed the name Heidi to Howard for half of the students (8). Both Heidi and Howard were rated as equally competent by the students, however, they characterized Heidi as more selfish, aggressive, power hungry and self-promoting than Howard, who was clearly more likeable.

So, how do we address this? In my experience, as a woman, you need to be aware of this bias in order to combat it. Avoid trying to fit in by mimicking male leaders with even stronger, aggressive behavior can make the situation worse. Alternately, trying to be liked at all costs, is equally dangerous. I have often been in a situation where I was the only woman at the table, where all of my peers, even those on my direct team were all male-not a single woman, not even the Human Resources manager. My recipe is a simple one: Be yourself, be authentic! Do not think about it, do not even start to worry or put yourself in doubt, as people tend to sense this and you will undermine your own efforts.

My experience has shown me that authenticity will always win because it helps you focus on the job rather than appearances. People will see that it is all about the job and not about you. And the good news is that if you have made it this far, your intellectual capacity and work performance must be outstanding, most likely better than anyone else's around you. By staying authentic and focusing on your strengths, people will recognize the professionalism and expertise you bring to the table and you will quickly earn the respect of everyone around you. Authenticity can serve as a foundation of trust and collegiality strengthening professional relationships and is a much more sustainable approach to work than striving to fit an ideal or mold of something that is not you.

\section{Play to your strengths}

Another asset is that often females have qualities that should be highlighted as strengths. Female leaders tend to be more collaborative, democratic or inclusive, relationship-oriented and have a horizontal perspective as opposed to a vertical one. This means that women can see a broader perspective and are better at identifying connections between different situations. Women also tend to be more empathic and therefore can be perceived as less threatening to other male colleagues. Some studies show that when women are empowered to meaningfully participate in conflict resolution, it undeniably results in more lasting peace (9). Women can build on these innate qualities and leverage them for the benefit of their work. I have consciously used 
these qualities with many of my male colleagues, including peers and bosses. I have garnered trust by building on my experience and competence and leveraged empathy to build strong teams and create a sense of belonging. My ability to put myself in my teams', peers' or bosses' shoes has allowed me to break down ego barriers, point out issues and draw connections that they may not have seen; basically, helping them in non-threatening ways. You can apply these qualities, or even better, use assessments such as the Strengths Finder by Tom Rath (8) to really understand and fully play to your personal strengths.

\section{Take a seat at the table}

The sad parallel between medicine and medical industry is that only $18 \%$ of hospital CEOs and $16 \%$ of all deans and department heads in the U.S. are women-positions that typically lead the mission and control the allocation of resources in medical centers (9). The picture worsens further when it comes to scientific literature. Just $10 \%$ of senior authors and only $7 \%$ of chief editors of renowned medical journals are female (10). Again, we see many similarities with women in business, where the statistics are nearly identical. So, why is this the case and what can we do about it?

One aspect to consider is the phenomenon known as the "confidence gap", typically applied to women $(11,12)$. Simply put, if you ask a male leader how he became successful, you will hear things like "I worked hard, made the right decision, took risks and succeeded." Yet, if you ask a woman, you will hear "I was lucky, was at the right time at the right place, someone helped me and supported me". Sheryl Sandberg describes this very well in her book Lean In when she stated: "There are still days I wake up feeling like a fraud, not sure I should be where I am" (13).

Therefore, women tend not to raise their hand as easily as men when it comes to a grant, a promotion, or applying for a bigger role. This is nicely illustrated in a study that reviewed thousands of personal records at Hewlett-Packard (HP) and systematically analyzed the applicants and the way they applied. It turned out that that women working at HP only applied for a promotion if they believed they met 100 percent of the qualifications listed for the job. Men were happy to apply when they thought they could meet $60 \%$ of the job requirements (14). My recommendation is to fight this need for perfectionism that we all feel so strongly. Know your accomplishments, know you earned it and be confident about taking your next steps. Raise your hand and take a seat at the table. You will be amazed how far you can go.

\section{Be mentored and become one}

Last, but not least, I would like to stress the importance of mentors. Most readers are already familiar with Nina Braunwald, one of the first three female cardiothoracic surgeons in the U.S. and the first one to perform a successful prosthetic mitral valve replacement. The articles about her consistently mention the importance of the mentorship of Dr. Hufnagel and Dr. Morrow $(15,16)$. I too, am tremendously grateful for my mentors and role models along the way who have pushed me to take new roles that I would have never dared to pursue. Find mentors and role models. Force yourself to network and connect with your colleagues and bosses in new ways by being authentic and playing to your strengths.

By doing this, you will yourself become the mentor and role model you are wishing for now. You will become the one to give confidence to colleagues, push them to raise their hand and pave the way for future generations. We can then change the statistics together and create a new future, where people will no longer say "Meredith Grey" [fictional character from the popular television show, Grey's Anatomy] when they are asked about a thriving female surgeon. A future where this image is no longer fiction but reality. In other words, a future where we just speak about surgeonsnot female surgeons.

\section{Inspiring women to thrive, personally and professionally at Medela}

As a woman leader of an organization committed to women's health, and a mother who has pursued career growth alongside motherhood responsibilities, I am personally dedicated to improving the opportunities available to mothers in the workplace. Medela has made it a goal to play an active role in helping moms return to work and allow for work-life balance, equally for our customers and our employees. By providing programs that include flexibility and support for breastfeeding at work, we can provide a smoother transition back to work after baby for our new parent employees: \#newmomshealthyreturns

With all Medela offices having strong female representation, ranging between $48 \%$ and $69 \%$, we recognize that we have an opportunity to tackle the "motherhood penalty", one of the big potential career 
derailers for women today. Diversity, inclusion, pay equality and representation of women in leadership positions will drive the success of the future and thankfully that is recognized by companies around the world that align and support the United Nations Compact. My continued commitment as a leader is to inspire Medela employees to thrive in their workplace and personal lives by offering mentoring and leadership exchange programs to be champions of equality, diversity and inclusion everywhere they go.

\section{Emily Elswick}

\section{Vice President \& General Manager, Lung Health, Minimally Invasive Therapies Group Medtronic}

\section{Igniting women to lead}

I started in healthcare in the early 2000s. Few women were sales representatives in the medical device industry, especially in the operating room. I called on thoracic surgeons daily. It was primarily a man's world on both sides of the table. Sales were done in the men's locker room before a procedure even started. I had to work smarter and build relationships that withstood the status quo at all levels. My goal was to help shape an environment where women could thrive, advance and ultimately lead. Now managing a business for Medtronic, I see how far the industry has come. During STS 2020, Douglas E Wood, MD, Chair of Thoracic Surgery at the University of Washington challenged the community to "continue to work to have a specialty better represent the patients we serve, and by that, I mean $50 \%$ women." His tweet came on the heels of the Women in Thoracic Surgery reception at the conference. The timing of the tweet was perfect; I had just attended a meeting with leaders across Medtronic where we spent time strategizing on our goal of $40 \%$ women in manager and above positions by 2020 . We also discussed our aspirational goal of $50 \%$ ! It was a validation of our alignment and the admiration I have for organizations putting diversity and inclusion at the center of their vision and mission.

Our Medtronic Mission is to alleviate pain, restore health and extend life. This mission was penned by our co-founder Earl Bakken over 50 years ago. The Medtronic Mission is composed of tenets-focus areas-that guide our business objectives. For me, our fifth tenet brings diversity and inclusion to life; and one of the reasons I am proud to work for Medtronic: To recognize the personal worth of all employees by providing an employment framework that allows personal satisfaction in work accomplished, security, advancement opportunity, and means to share in the company's success.

Earl Bakken also crafted a dream sheet over the years. Dreams he had for the future and areas to make meaningful advancements. One specific dream was "A WORLD WHERE WOMEN LEAD.” That dream sheet isn't just a piece of paper. Medtronic is committed to the development and advancement of women. We established a women's group over 30 years ago with a few brave women and over time it became a formal employee resource group (ERG) with over 15,000 members worldwide. The Medtronic Women's Network has three strategic imperatives:

* Activate leaders of people to develop and advance women.

* Be recognized as a best place for women to work.

* Empower women to come here, grow here, lead here.

In March 2020, Medtronic will be recognized in New York City as one of three Catalyst Award winners. Catalyst is a global nonprofit that works with CEOs and leading companies to build workplaces that work for women. The Catalyst Award is given in recognition of innovative organizational initiatives including recruitment, development, and advancement of all women and has been given to 90 organizations from around the world since 1987 (https://www.catalyst.org/solution/catalyst-award). Medtronic earned this award for our initiatives advancing women and creating an inclusive workplace. We have a strong focus on globalization and women in science and engineering. This marries well with what we are seeing in the commitment and growth of Women in Thoracic Surgery (WTS). The efforts we put forward continue to impact our employees and shape how we partner with physicians around the globe. We have been proud supporters of WTS for many years, but we cannot stop with support alone. I think we can go further, together.

We can start a dialogue, partner to raise awareness, collaborate to educate on unconscious bias, and inspire a culture of mentorship and sponsorship that truly brings women into the lung cancer arena and places women in leadership roles. We can model what the future of thoracic surgery and lung cancer management can be; an equally represented workforce of strong, passionate, collaborative, and inspiring female leaders. We envision a world where women lead in creating a lung cancer stage shift moving it from a death sentence to a managed condition where patients can have a good quality of life. And, with an 
increase in women under 40 getting lung cancer; why not us, why not now? Women, let's come together and, raise each other up. Men come along side us; be an ally, provide opportunities for exposure, advance the conversation, advocate for women, and for change. We can truly go further together and make Earl Bakken's dream a reality. As a woman leader, a wife, and a mother of three; this is what fuels me: Inspiring a culture of inclusion around the world and showing the long-term results and positive impact we can make when diversity and inclusion are at the heart of how we do what we do.

\section{Kate Masschelein}

\section{President of Ethicon Energy in Fohnson \& Fohnson Medical Devices}

\section{Women in healthcare: advancing our opportunities} from both sides of the operating table

I have enjoyed working for Johnson \& Johnson for the last 16 years and have had the pleasure of learning from many great leaders, both male and female, throughout my tenure. I'm truly grateful for their advice and for the opportunities they've helped me identify throughout my corporate and personal journeys. I hope sharing some of my insights will positively support emerging women leaders and enhance their leadership journey whether they are in healthcare or the corporate world.

I am fortunate to work for an organization like Johnson \& Johnson, one of the largest healthcare companies in the world, who has, in many ways, led the advancement of equal opportunities for women. In fact, Johnson \& Johnson started its strong legacy of supporting women by hiring eight female employees (over half of its 14-person staff) when they first started in 1886 . Today, women represent close to $50 \%$ of J\&J's worldwide workforce. Diversity and inclusion continue to be a priority focus for the company.

In 1995, J\&J helped establish the Women's Leadership \& Inclusion (WLI) organization across the enterprise. Through this Employee Resource Group, women and men across the globe can participate in discussions and events that help promote equality and support throughout our workforce. We are celebrating WLI's $25^{\text {th }}$ birthday in March. Being part of WLI, as an employee, has given me so much in terms of coaching, confidence and a supportive network. Today I'm a campus sponsor for WLI in Cincinnati to give back to the community.

In 2017, WLI partnered with the Society of Surgical
Chairs (SSC) Women's Committee, to help create the Women in Surgery symposium hosted by Ethicon, Inc. The first edition of this symposium, themed "Leading through Change," was dedicated to supporting female surgeons by providing a forum to discuss the challenges they face and by providing opportunities for mentorship. We discovered that there are a lot of similarities between the challenges that female surgeons face and those of women in a corporate environment. We also found that having, and being, mentors was very helpful in advancing to higher leadership levels. The symposium was such a success that we held a second symposium in 2018, themed "Managing Up, Down and Sideways." It focused on joining forces to improve opportunities and create ongoing dialogue to advance female surgeons. Additionally, J\&J has been a strong partner supporting the Association of Women Surgeons (AWS) annual conference and has sponsored The Sewing Circle—a group dedicated to connecting and supporting female surgeons.

As I think about the challenges of my female colleagues in healthcare and the challenges of being a woman in a corporate world, I believe there are three personal and three professional practices that can help any leader excel—and help overcome gender challenges.

\section{Express what you want}

We often think working hard and meeting expectations will get us noticed and promoted to different rolesand that stating our advanced or executive goals can be regarded as too aggressive. As we enter the workforce in our twenties, we have a long road ahead until retirement in our sixties. I learned early in my career, the importance of communicating how I wanted to shape my career, what my ultimate career goal was and sought advice on how to get there. It helped my mentors and managers to guide me along the way.

\section{Believe in yourself}

Over the past 16 years, I've taken on roles in different functions, different countries and multiple companies within $\mathrm{J} \& \mathrm{~J}$, which can be both very exciting and daunting at the same time. With every new opportunity I would experience the well-known imposter syndrome, i.e., the belief that I am not capable to take on the new role. This can be stifling and it is also untrue. It takes courage and resilience, but taking on roles beyond your comfort zone allow you to develop yourself in new ways, which in turn builds confidence.

\section{Give back}

The more I advanced in my career, the more I realized the importance of giving back by supporting female colleagues as they progress through their careers with advice, sharing 
my experiences, my mistakes, and helping open doors by connecting them with right people, after they've expressed what they are looking for in their careers.

\section{Take care of yourself}

Part of being a leader is to help guide others around us, but we can't help others be their best, if we don't feel our best. We give a lot of ourselves to our careers, and I know that if I don't get enough sleep, I don't eat well or don't exercise regularly, I don't make mindful decisions, feel more stressed and am not fully present in meetings. I know it takes a toll on my health. Building a successful career really is a marathon.

\section{Do what you love}

I once had to make a choice between two great career opportunities, so I asked a mentor for advice. Beyond the rational pros and cons of each option, he told me to choose what I think I would love most. I thought that was an uncommon perspective. His view was that our careers span over 30, 40 years. We will spend a large part of our lives at work. Doing what you love, makes life more enjoyable. When you love what you do, you will be more successful and feel more confident as well. So, this is part of my advice to others, do what you love.

\section{The value of friends and family}

We spend a lot of time at work and sometimes face tough decisions and challenging projects. My family and friends help me put a pause on all this. It helps me gain perspective and clarity. It reminds me that I'm not just who I am at work, that I'm a whole person.

\section{Conclusions}

The barriers to promotion, advancement, and leadership facing women within thoracic surgery are well-documented, however they are not unique to our field. In many ways, we are very similar to some of our closest non-physician partners working alongside us in the medical industry. Drawing upon these commonalities women in thoracic surgery can use some of these best practices borrowed from our industry partners as a guide to developing new programs or expanding existing programs to improve gender equity in thoracic surgery. Ultimately, we share a common goal to chart a course towards creating a more diverse workforce in thoracic surgery that more closely resembles the patients we serve.

\section{Acknowledgments}

Funding: None.

\section{Footnote}

Provenance and Peer Review: This article was commissioned by the editorial office, Fournal of Thoracic Disease for the series "Women in Thoracic Surgery". The article has undergone external peer review.

Conflicts of Interest: The authors have completed the ICMJE uniform disclosure form (available at http://dx.doi. org/10.21037/jtd-2020-wts-02). The series "Women in Thoracic Surgery" was commissioned by the editorial office without any funding or sponsorship. LB and CP served as the unpaid Guest Editors of the series. CP serves as an unpaid editorial board member of Journal of Thoracic Disease from Sep 2020 to Aug 2022. AB is currently the CEO of Medela. EE reports other from Medtronic, from null, outside the submitted work. The authors have no other conflicts of interest to declare.

Ethical Statement: The authors are accountable for all aspects of the work in ensuring that questions related to the accuracy or integrity of any part of the work are appropriately investigated and resolved.

Open Access Statement: This is an Open Access article distributed in accordance with the Creative Commons Attribution-NonCommercial-NoDerivs 4.0 International License (CC BY-NC-ND 4.0), which permits the noncommercial replication and distribution of the article with the strict proviso that no changes or edits are made and the original work is properly cited (including links to both the formal publication through the relevant DOI and the license). See: https://creativecommons.org/licenses/by-nc-nd/4.0/.

\section{References}

1. Olive JK, Preventza OA, Blackmon SH, et al. Representation of Women in The Society of Thoracic Surgeons Authorship and Leadership Positions. Ann Thorac Surg 2020;109:1598-604.

2. Bellini MI, Graham Y, Hayes C, et al. A woman's place is in theatre: women's perceptions and experiences of working in surgery from the Association of Surgeons of Great Britain and Ireland women in surgery working group. BMJ Open 2019;9:e024349.

3. Laskar M, Spinosi AM, Bendjebla Y, et al. Are we running out of thoracic or cardiac surgeons? Demography of 
thoracic and cardiac surgeons in France in 2012. Interact Cardiovasc Thorac Surg 2013;16:470-4.

4. Lauren Tousigant. More women than men attending med school for the first time ever. The New York Post. 2017, Dec 21. Available online: https://nypost.com/2017/12/21/ more-women-than-men-attending-med-school-for-thefirst-time-ever/

5. Brendan Murphy. These Medical specialties have the biggest gender imbalances. American Medical Association. 2019. Available online: https://www.ama-assn.org/ residents-students/specialty-profiles/these-medicalspecialties-have-biggest-gender-imbalances

6. Claire Zillman. The Fortune 500 has more female CEOs than ever before. 2019, May 16. Available online: https:// fortune.com/2019/05/16/fortune-500-female-ceos/

7. Bickel J. Gender equity in undergraduate medical education: a status report. J Womens Health Gend Based Med 2001;10:261-70.

8. Tom Rath. Strengths Finder 2.0. New York: Gallup Press, 2013.

9. Mangurian C, Linos E, Sarkar U, et al. What's Holding Women in Medicine Back from Leadership. Harvard Business Review. 2018, June 19. Available online: https://

Cite this article as: Pompili C, Brüls A, Elswick E, Masschelein $\mathrm{K}$, Backhus L. Women in thoracic surgery: lesson learned from medical industry partners. J Thorac Dis 2021;13(1):485-491. doi: 10.21037/jtd-2020-wts-02 hbr.org/2018/06/whats-holding-women-in-medicineback-from-leadership

10. Jagsi R, Guancial EA, Worobey CC, et al. The "gender gap" in authorship of academic medical literature - a 35 year perspective. N Engl J Med 2006;355:281-7.

11. Katty Kay, Claire Shipman. The Confidence Gap. The Atlantic. 2014, May

12. Guilen L. Is the Confidence Gap Between Men and Women a Myth?. Harvard Business Review. 2018, March 26. Available online: https://hbr.org/2018/03/is-theconfidence-gap-between-men-and-women-a-myth

13. Sandberg S. Lean In: Women, Work, and the Will to Lead. Alfred A. Knopf Edition. 2013.

14. Katty Kay, Claire Shipman. The Confidence Gap. The Atlantic. 2014, May. Available online: https:// www.theatlantic.com/magazine/archive/2014/05/theconfidence-gap/359815/

15. Waldhausen JA. In Memoriam: Nina S. Braunwald. 19281992. Ann Thorac Surg 1993;55:1055-6.

16. Sabharwal N, Dev H, Smail H, et al. Nina Braunwald: A Female Pioneer in Cardiac Surgery. Tex Heart Inst J 2017;44:96-100. 